\title{
Screening freshness of seafood by measuring trimethylamine (TMA) levels using helium-plasma ionization mass spectrometry (HePI-MS)
}

\author{
Isuru S. Herath', Thomas E. O'Donnell ${ }^{2}$, Julius Pavlov² and Athula B. Attygalle $2^{2^{*}}$ (D)
}

\begin{abstract}
Background: Trimethylamine (TMA) is a marker used for monitoring the quality of seafood because it is the primary component of the "fishy" odor.

Methods: The levels of TMA in seafood samples were directly measured by helium-plasma ionization mass spectrometry (HePI-MS). Each sample was directly exposed to the HePI source, and the intensity of the $\mathrm{m} / \mathrm{z} 60$ signal for protonated TMA was monitored by a selected-ion-recording (SIR) protocol. Using a set of TMA-spiked water standards, the TMA levels in seafood samples were quantified.

Results: The signal intensity of the $\mathrm{m} / \mathrm{z} 60$ ion from shrimp samples maintained at room temperature for 2 days can be attenuated to baseline levels by adding lime juice. The amounts of TMA in samples of salmon and shrimp recovered from some sushi preparations, and in squid samples, were found to be $0.24 \mu \mathrm{g}, 0.16 \mu \mathrm{g}$, and $17.2 \mu \mathrm{g}$ per gram, respectively.
\end{abstract}

Conclusions: HePI-MS is an efficient technique to screen and monitor the TMA content and assess the quality of seafood.

Keywords: Trimethylamine (TMA), Helium-plasma ionization, HePl, Ambient mass spectrometry, Seafood quality, Fish odor, Screening freshness of seafood

\section{Introduction}

Fresh seafood is highly perishable and therefore requires utmost care during processing, transportation, and storage in order to prevent decomposition. Approximately 200 million metric tons of seafood is directly consumed by people globally per annum as reported by the UN Food and Agricultural Organization. Despite the high perishability, many connoisseurs prefer consuming seafood preparations raw or only lightly preserved. As a result, the market has recently seen an increasing demand for fresh seafood. Thus, in order to meet consumer demands and comply with legislative regulations, a quality assessment performed on the product before it is offered

\footnotetext{
* Correspondence: Athula.attygalle@stevens.edu

${ }^{2}$ Department of Chemistry and Chemical Biology, Stevens Institute of Technology, Hoboken, NJ 07030, USA

Full list of author information is available at the end of the article
}

to the consumers is of paramount importance. In seafood, biogenic amines are formed upon storage thorough enzymatic and microbial action on amino-acids. Among the biogenic amines, trimethylamine (TMA) is the primary component that imparts the fishy odor (Bedia Erim 2013). Thus, TMA is commonly used as a marker to qualitatively and semi-quantitatively detect the spoilage of fish (Oetjen and Karl 1999; Pedrosa-Menabrito and Regenstein 1990; Timm and Jørgensen 2002). TMA is produced by the oxidation of choline by bacteria in marine animals by TMA-lyase. TMA also accumulates by the reduction of trimethylamine $N$-oxide (TMAO) by the enzyme TMAO reductase in the tissues of decaying marine animals. TMA is toxic to humans: it is oxidized in the liver to form TMAO (Seibel and Walsh 2002), which has been recognized as an agent that causes cardiovascular disease (Landfald et al. 2017). 
Several sensory- and instrument-based techniques are available to monitor the quality of seafood. Most of these methods rely on the detection of TMA, which is one of the main compounds responsible for the malodor of poor-quality seafood (Oetjen and Karl 1999; Timm and Jørgensen 2002). The correlation between extracted TMA and the age and quality of seafood has been welldemonstrated (Malle et al. 1996; Malle and Tao 1987; Oetjen and Karl 1999; Romero-González et al. 2012; Timm and Jørgensen 2002).

More elaborate instrumental methods have evolved through the years. At present, gas chromatography (Namieśnik et al. 2003; Shim and Baek 2012), solidphase micro-extraction (Chan et al. 2016; Shim and Baek 2012), or solvent extraction (daCosta et al. 1990; Oetjen and Karl 1999), ion mobility (Bota and Harrington 2006; Cheng et al. 2017), nuclear magnetic resonance spectroscopy (Podadera et al. 2005), ion chromatography (Erupe et al. 2010; Li et al. 2009), capillary electrophoresis ( $\mathrm{Li}$ and Lee 2007; Timm and Jørgensen 2002), high-resolution rotational terahertz (THz) spectroscopy (Hindle et al. 2018), and high-performance liquid chromatography methods (Cháfer-Pericás et al. 2004; Hyötyläinen et al. 2001; Romero-González et al. 2012) are the most widely adopted techniques to measure the amounts of primary and secondary amines in various matrices. The major advantages of these chromatographic techniques are higher sensitivity, specificity, and ability to determine several substances simultaneously.

A drawback of many traditional analytical techniques employed to determine the quality of seafood is the time-consuming and laborious TMA extraction step, and the difficulty in handling low-molecular-mass amines due to their high water solubility and volatility. The technique we have developed-based on ambientpressure helium-plasma ionization mass spectrometry (HePI-MS)-does not require the TMA extraction step or chromatographic separation.

In this study, we employed ambient-pressure HePI-MS (Yang and Attygalle 2011) to screen the freshness of seafood, because the technique affords a direct measurement of TMA levels in samples, without the need to resort to chemical extraction, or any other prior sample preparation. HePI is a versatile ambient-ionization MS technique, applicable to the analysis of a wide variety of samples, both organic and inorganic. It has been applied, for example, to the analysis of energetic materials (Yang et al. 2012), pharmaceutical preparations (Attygalle et al. 2014a, 2014b, Xia et al. 2016), halobenzenes (Attygalle et al. 2014a, 2014b; Gangam et al. 2015), phenolics and

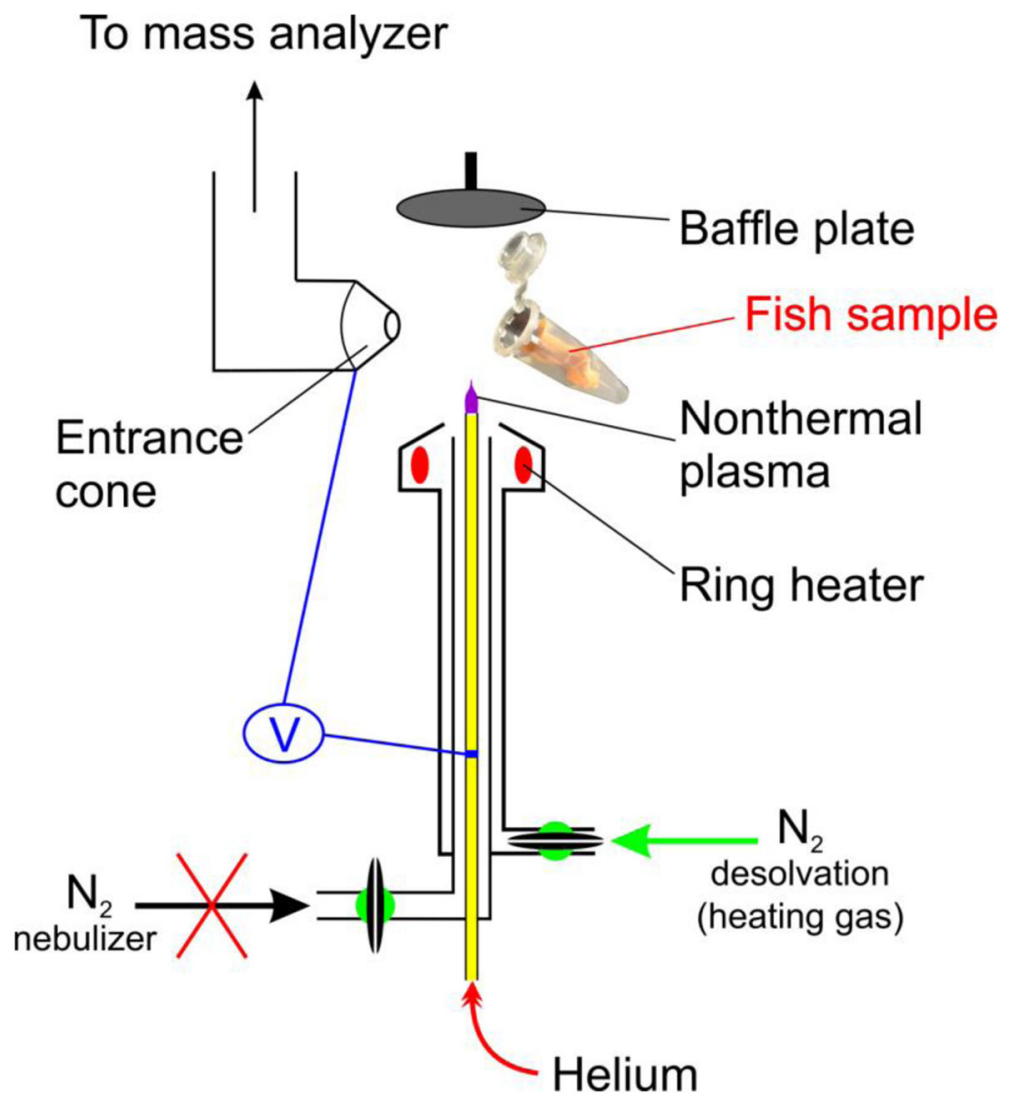

Fig. 1 A schematic diagram illustrating a HePI ion source. A fish sample in an Eppendorf tube was exposed to the ambient ion source 
quinones (Hassan et al. 2017), inorganic nitrates (Pavlov and Attygalle 2013), and inorganic mercury compounds (Weerasinghe et al. 2014). A major advantage of HePI is that it is highly portable and adaptable: any mass spectrometer with an electrospray ion source can be transformed into an ambient HePI instrument with ease, and no extensive hardware modifications are necessary (see Experimental Section). In addition, unlike other helium- mediated sources such as Direct Analysis in Real Time (DART) and Flowing Atmospheric-Pressure Afterglow (FAPA), HePI is extremely economical in its helium consumption. Another important feature of HePI is that if a sample is sufficiently volatile or can be volatilized, it can be detected without any significant interference from the sample matrix. In this study, we investigated the capabilities of HePI to measure TMA levels in several seafood

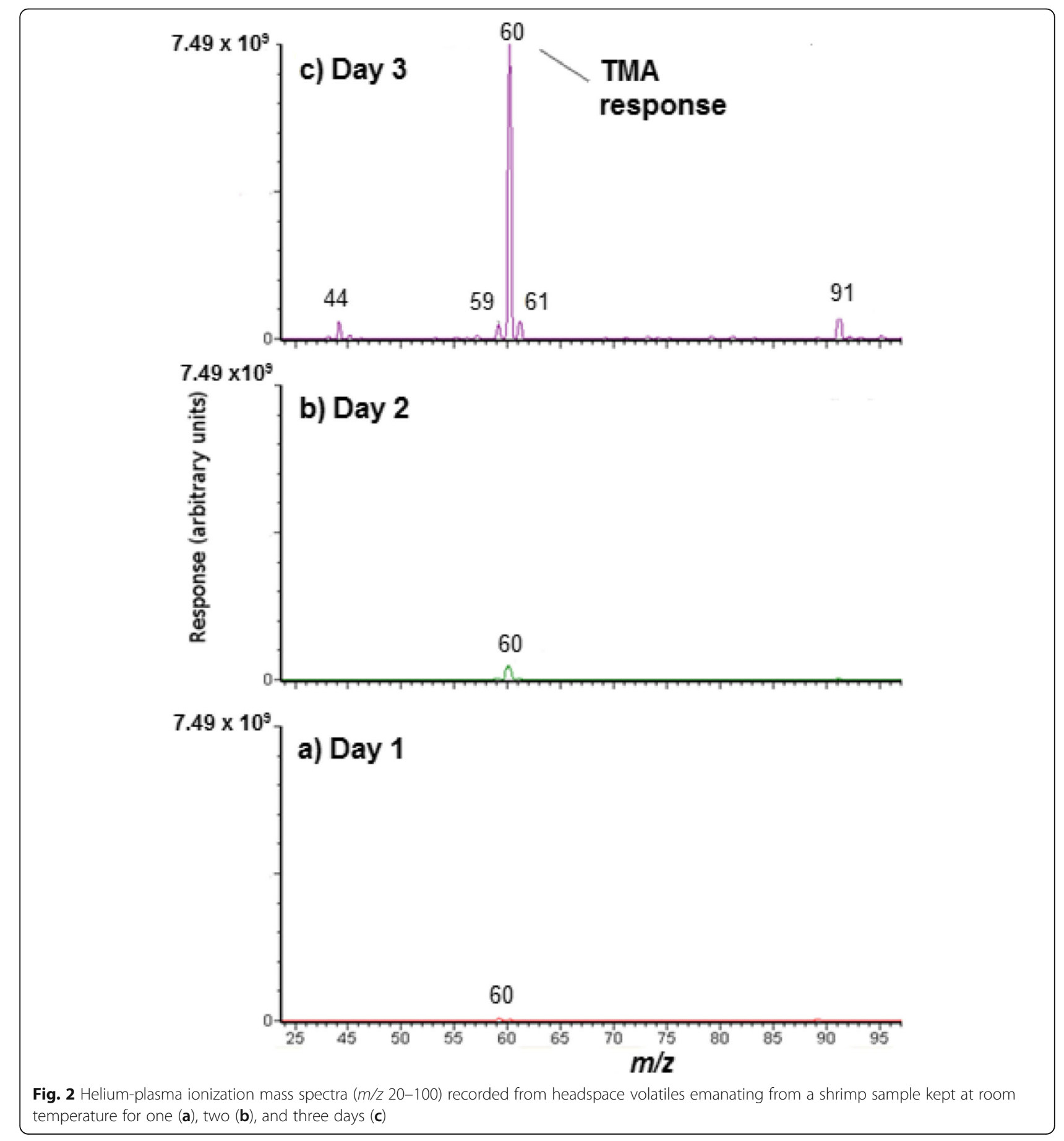


samples from various specimens of fish at different time points of storage at room temperature (0 to $96 \mathrm{~h}$ ). Additionally, the reduction of the amount of free TMA by the addition of lime juice, similar to the action of many other common acidic seafood condiments (e.g., lemon juice and tartar sauce), was demonstrated.

\section{Methods}

\section{Materials and sample preparation}

High-purity helium (99.999\%, Airgas, Radnor, PA) was used for all experiments. Trimethylamine was purchased from Sigma-Aldrich Co. (St. Louis, MO, USA). Concentrated hydrochloric acid and $\mathrm{NaHCO}_{3}$ were purchased from Fisher Scientific (Hampton, NH). Lime juice
(ReaLime ${ }^{\bullet} 100 \%$ ) and samples of seafood [cod, char, salmon, and squid (mantle only, not the tentacles)], displayed on ice, were purchased from a local store (Wegmans, Woodbridge, NJ) and transported to the laboratory on a bed of ice. Similarly, samples of shrimpand salmon-sushi, and fresh squid samples were purchased from the same store, and a sample of fresh shrimp was obtained from another local store (99 Ranch Market, Jersey City, NJ). From each seafood, eighteen representative samples $(25 \mathrm{~mm} \times 3 \mathrm{~mm} \times 3 \mathrm{~mm} ; 0.8 \mathrm{~g}$ each) were separated and placed in Eppendorf tubes (2.0 $\mathrm{mL}$ ), which were kept at room temperature with lids tightly closed. For shrimp, the representative samples were cut from the region immediately below the head,

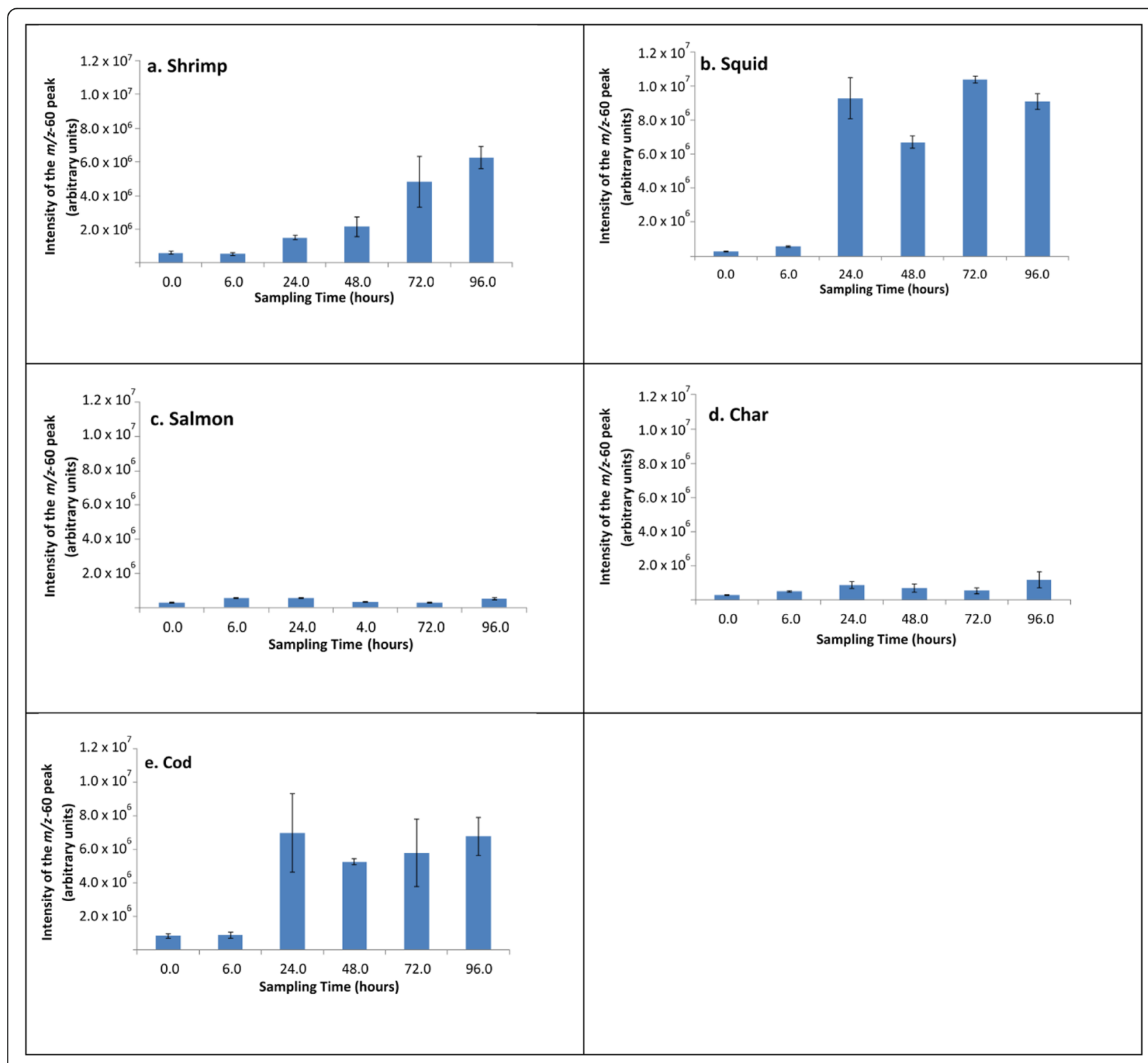

Fig. 3 Intensity of the $m / z 60$ signal for protonated TMA recorded from headspace volatiles of shrimp (a), squid (b), salmon (c), char (d), and cod (e) samples $(N=6)$ kept at room temperature for $96 \mathrm{~h}$. 


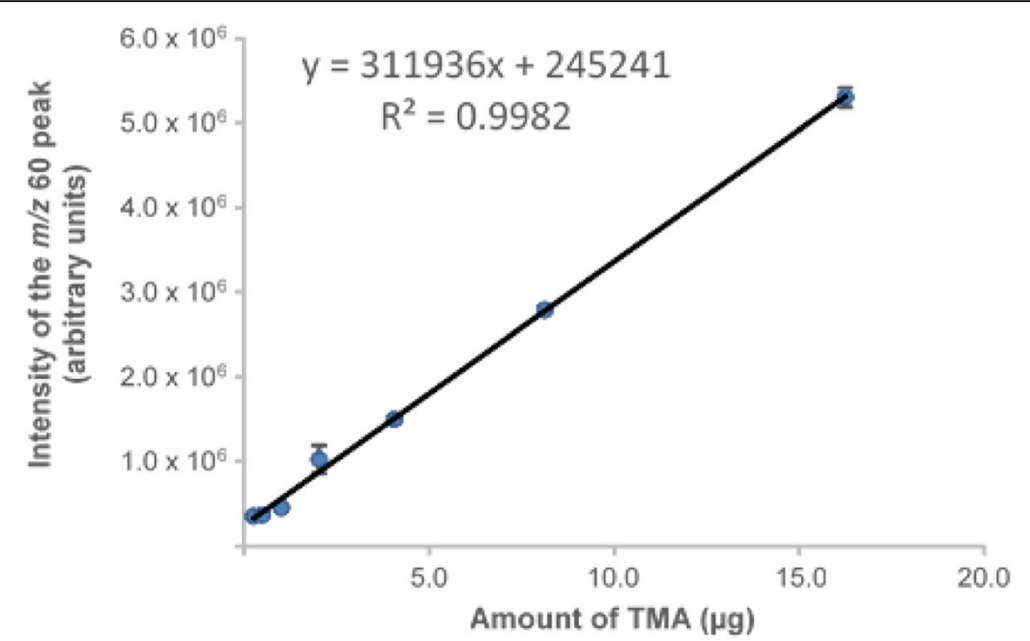

Fig. 4 Plot of average areas of $m / z 60$ peak for protonated TMA generated from standard solutions in water $(N=6)$

and for the sushi samples, samples were prepared only from the meat portion.

\section{Mass spectrometric analysis}

A stream (25-30 $\mathrm{mL} / \mathrm{min})$ of high-purity helium (99.999\%, Airgas, Radnor, PA, USA) was passed through a metal capillary $(100 \mu \mathrm{m}$ ID) held at a high voltage (typically, $3 \mathrm{kV}$ ) for it to function as a helium-plasma ionization source, as described previously (Yang and Attygalle 2011). The capillary was placed at a $90^{\circ}$ angle, about $10 \mathrm{~mm}$ away from the outer cone orifice of a single-quadrupole mass spectrometer (ZQ model, Waters Corp., Milford, MA, USA). Positive-ion mass spectra were recorded from headspace volatiles emanating from each sample (Fig. 1).

Prior to analysis, each Eppendorf tube containing a sample was opened and attached to the inner side of the ion-source glass cover. Mass spectra were acquired $(\mathrm{m} / \mathrm{z}$ 25-200) at a rate of 2 scans per second, and the results were processed using MassLynx 4.0 software (Waters Corp., Milford, MA, USA). The cone voltage was held at $15 \mathrm{~V}$; the source and desolvation gas temperatures were both maintained at $110{ }^{\circ} \mathrm{C}$. After each analysis, the ion source was cleaned thoroughly by wiping it with a cotton swab soaked in methanol, and a background check was made to ensure that the $m / z 60$ signal intensity had returned back to the background level before a new sample was introduced.

Three samples of each seafood (cod, char, salmon, shrimp, and squid), maintained inside Eppendorf tubes at room temperature, were analyzed at $0,6,24,48,72$, and $96 \mathrm{~h}$. Each tube containing a sample was opened and placed immediately in the HePI source. The tube neck was positioned at a pre-determined fixed point at $1.0 \mathrm{~cm}$ distance from both the entrance-cone orifice and the HePI plasma flame. The amount of TMA emanating from each sample was recorded for $0.5 \mathrm{~min}$ by a selected-ion-recording (SIR) experiment monitoring the abundances of the $m / z 60$ and 61 ions (dwell time $0.1 \mathrm{~s}$; inter-scan delay $0.1 \mathrm{~s}$ ). Each sample was analyzed in duplicate by the SIR procedure. Then, the average $m / z 60$ peak intensity and that of $m / z 61$ were calculated for each 0.5 min acquisition period.

\section{Trimethylamine standard curve}

The concentration of the commercial TMA solution was determined to be $3.5 \mathrm{M}$, by titrating it against a $0.12 \mathrm{M}$ standard $\mathrm{HCl}$ solution, using methyl orange as the indicator. The $\mathrm{HCl}$ solution was standardized using $\mathrm{NaHCO}_{3}$ as a primary standard.

A stock solution of TMA $(1300 \mu \mathrm{g} / \mathrm{mL})$ was prepared from the 3.5M TMA solution and diluted quantitatively to make a series of standards $(650,325,162.5,81.3,40.6$, $20.3,10.2,5.1,2.5$, and $1.3 \mu \mathrm{g} / \mathrm{mL})$. Aliquots of each standard $(200 \mu \mathrm{L})$ were transferred to Eppendorf tubes, and the intensity of the $\mathrm{m} / \mathrm{z} 60$ ion generated from the headspace of each sample was monitored by an SIR experiment conducted under HePI-MS conditions. A standard curve was generated by plotting the intensity of

Table 1 TMA amounts found in some sushi and squid samples

\begin{tabular}{ll}
\hline Sample & $\begin{array}{l}\text { Average amount } \\
(\mu \mathrm{g} / \mathrm{g})\end{array}$ \\
\hline Squid sample $(0.8 \mathrm{~g})$ & 17.2 \\
$\begin{array}{l}\text { A piece of salmon recovered from a } \\
\text { sushi sample }(0.8 \mathrm{~g})\end{array}$ & $\sim 0.24^{\mathrm{a}}$ \\
$\begin{array}{l}\text { A piece of shrimp recovered from a } \\
\text { sushi sample }(0.8 \mathrm{~g})\end{array}$ & $\sim 0.16^{\mathrm{a}}$ \\
\hline
\end{tabular}

${ }^{\mathrm{a}}$ Amounts estimated by extrapolating the calibration curve 
the $m / z 60$ ion peak in six replicates, against the amount of TMA present in each sample.

\section{Estimating the freshness of seafood samples by the amount of TMA detected}

Samples from shrimp- and salmon-sushi, as well as squid were analyzed in duplicate, immediately after they were brought to the laboratory, by an SIR experiment. The peak intensity at $\mathrm{m} / \mathrm{z} 60$ was monitored for $0.5 \mathrm{~min}$ for each sample (dwell time $0.1 \mathrm{~s}$ ). Then, the average $\mathrm{m}$ / $z 60$ peak intensity was calculated for the total acquisition period of $0.5 \mathrm{~min}$.

\section{Effect of lime juice on TMA levels}

After recoding positive-ion spectra $(m / z 25-200)$ for 0.7 min, a 0.8-g sample of shrimp which had been kept at room temperature for $48 \mathrm{~h}$ was placed in the ion source. The volatiles emanating from the sample were monitored by recording a chronogram. After recording spectra for $1.2 \mathrm{~min}$, a $500-\mu \mathrm{L}$ aliquot of lime juice was added, using a pipette, to the shrimp sample, and spectra were acquired for another $1 \mathrm{~min}$.

\section{Results and discussion}

Initial studies conducted with seafood samples showed that a peak at $m / z 60$ for protonated TMA can be observed under HePI-MS conditions. The intensity of the peak was insignificant in the spectra recorded from the headspace volatiles of fresh shrimp samples (Fig. 2a). However, a dramatic increase of its intensity (and that of the peak at $m / z 61$ for the protonated ${ }^{13} C_{1}$-isotopologue of TMA) was noted in the spectra recorded from samples kept at room temperature for 3 days (Fig. 2c). Throughout the experiments, the relative intensity ratios of the $\mathrm{m} / \mathrm{z} 60$ and 61 peaks were monitored to ascertain the integrity of the recorded signal as being due to TMA.

In a study that monitored the TMA levels over a period of 4 days, we noted that the released amount of TMA increased gradually as the samples aged (Fig. 3). The increase of the $\mathrm{m} / \mathrm{z} 60$ levels could be attributed to

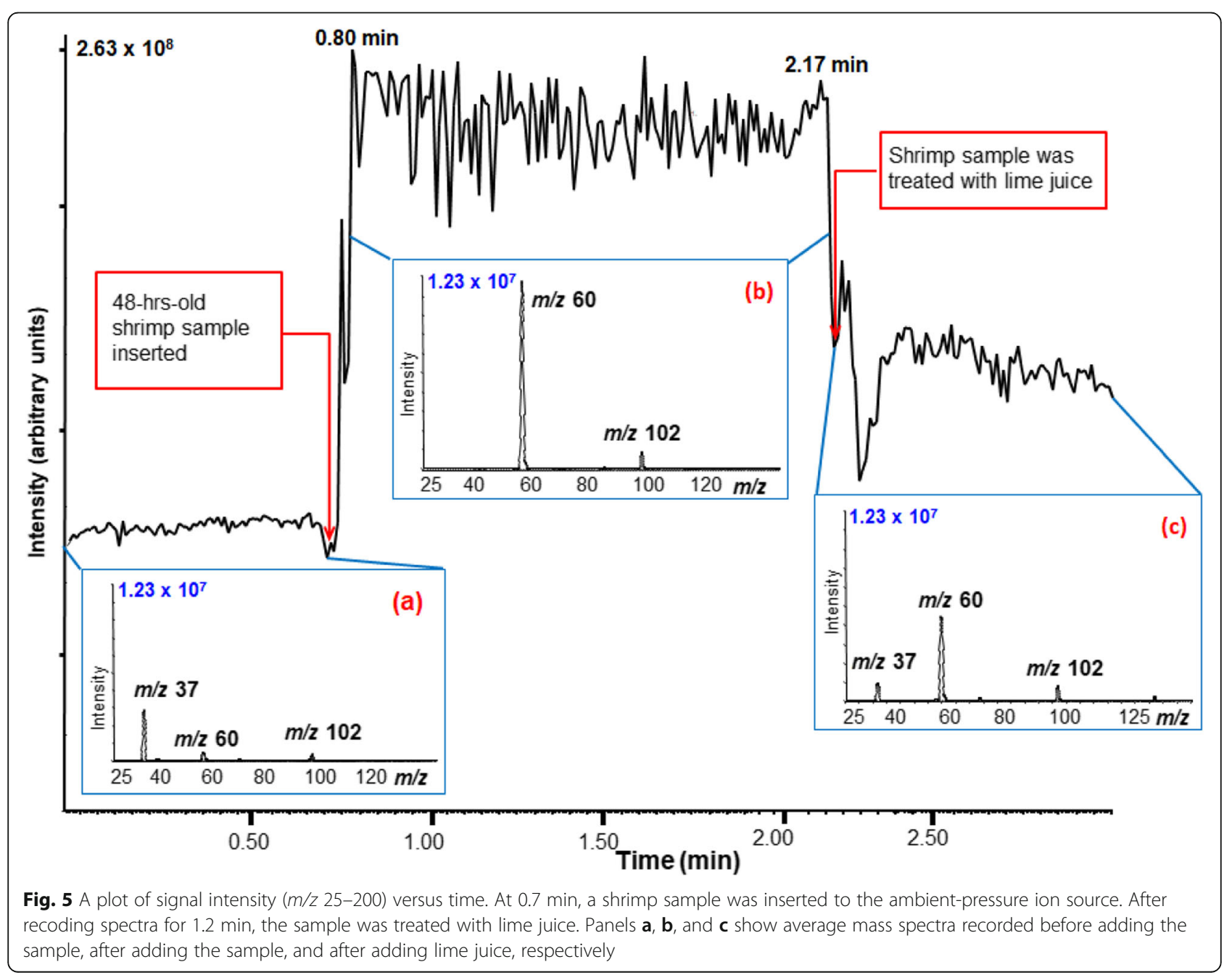


an increase of TMA because the $\mathrm{m} / z 61$ peak showed a proportionate increase in intensity. Subsequently, in a comparative study, the average intensities of the $m / z 60$ peak were calculated for each seafood sample kept at room temperature for different periods of time and plotted against the age of the sample. The results showed that the rate of increase of TMA levels for squid samples kept at room temperature was higher than that for shrimp samples. For squid, the TMA amounts in headspace volatiles reached levels beyond the dynamic range of the method within $48 \mathrm{~h}$ at room temperature (Fig. 3b). In contrast, the TMA levels in the shrimp samples showed a gradual increase over a period of $96 \mathrm{~h}$. Interestingly, the increase of TMA levels over time was relatively slower for fresh salmon and char samples (Fig. 3c, d). On the other hand, TMA emanating from cod reached a plateau level in $24 \mathrm{~h}$ (Fig. 3e).

To evaluate the linear dynamic range of quantification of the described method, a calibration plot was constructed by placing different amounts of TMA in the ion source. Figure 4 shows that intensity values increase linearly at least up to $16 \mu \mathrm{g}$ of TMA. Using this calibration curve, we estimated the amount of TMA released from a sample of squid or samples of salmon and shrimp removed from sushi rolls (Table 1). Evidently, this is a semi-quantitative method at best because the absolute amount of TMA present in unit amounts of seafood or fish samples was not determined in the current study.

A major advantage of ambient-ionization mass spectrometric methods of analysis is specifically the fact that signals for analytes of interest can be elicited even from very complex samples without any measurable matrix interference-TMA is a gas. Once it emanates from a sample, it can be ionized and detected very efficiently because unlike in electrospray ionization, it does not have to be desorbed from a solution. In the samples used in this study, the matrix consists mostly of fat and protein. Unlike in electrospray or MALDI techniques, fats and proteins do not undergo ionization directly by HePI, and therefore do not interfere with TMA signals.

\section{Masking of TMA odor with lime juice}

In many parts of the world, it is customary for seafood to be served along with an acidic condiment such as lemon juice or lime juice (citric acid), vinegar (acetic acid), or tartar sauce (tartaric acid). To demonstrate the reduction of the TMA levels by the addition of lime juice, the source background signals were recorded for a period of $0.7 \mathrm{~min}$. When a 48 -h-old shrimp sample was introduced, a dramatic increase of the intensity of $\mathrm{m} / \mathrm{z}$ 60 signal was noted (Fig. 5). The signal increase is caused by TMA accumulated in the headspace during the decomposition process. After the addition of lime juice, however, the signal abruptly dropped back to background levels. This is due to the acid-base reaction that takes place between the basic TMA in seafood and lime juice or other acidic condiments (e.g., lemon or tartar juice), which convert TMA to its much less volatile respective salt (Fig. 5).

\section{Conclusions}

The described method can be used to rapidly screen the quality of seafood in a high-throughput manner, due to the simplified sample preparation procedure, which does not involve the solvent extraction of the analyte. The amount of TMA present can be determined semiquantitatively. Herein, we have demonstrated that the reducing or completely eliminating the malodor associated with decaying seafood in seafood samples, by treating seafood with lime juice or vinegar, is due to reducing the amount of free TMA.

\section{Abbreviations}

HePI-MS: Helium-plasma ionization mass spectrometry; SIR: Selected-ion recording; TMA: Trimethylamine; TMAO: Trimethylamine N-oxide; UN: United Nations

\section{Acknowledgements}

The authors thank Ramu Errabelli, Sihang Xu, and Zhaoyu Zheng for helpful discussions.

\section{Authors' contributions \\ $\mathrm{IH}$ and TO carried out the experiments and collected, analyzed, and interpreted the experimental results. JP and ABA supervised the work and interpreted the experimental results. All authors contributed to the manuscript drafts, and read and approved the final manuscript.}

Funding

This work has not been financially supported.

Availability of data and materials

Not applicable.

\section{Competing interests}

The authors declare that they have no competing interests.

\section{Author details}

${ }^{1}$ Marriotts Ridge High School, 12100 Woodford Drive, Marriottsville, MD 21104, USA. ${ }^{2}$ Department of Chemistry and Chemical Biology, Stevens Institute of Technology, Hoboken, NJ 07030, USA.

Received: 12 June 2019 Accepted: 25 September 2019

Published online: 18 November 2019

\section{References}

Attygalle AB, Gangam R, Pavlov J. Real-time monitoring of in situ gas-phase H/D exchange reactions of cations by atmospheric pressure helium plasma ionization mass spectrometry (HePI-MS). Anal Chem. 2014a;86:928-35.

Attygalle AB, Jariwala FB, Pavlov J, Yang Z, Mahr JA, Oviedo M. Direct detection and identification of active pharmaceutical ingredients in intact tablets by helium plasma ionization (HePl) mass spectrometry. J Pharm Analysis. 2014b; 4:166-72.

Bedia Erim F. Recent analytical approaches to the analysis of biogenic amines in food samples. TrAC, Trends Anal Chem. 2013;52:239-47.

Bota GM, Harrington PB. Direct detection of trimethylamine in meat food products using ion mobility spectrometry. Talanta. 2006;68:629-35.

Cháfer-Pericás C, Herráez-Hernández R, Campins-Falcó P. Liquid chromatographic determination of trimethylamine in water. J Chromatogr A. 2004;1023:27-31.

Chan ST, Michael WY, Wong YC, Wong T, Mok CS, Della WMS. Evaluation of chemical indicators for monitoring freshness of food and determination of 
volatile amines in fish by headspace solid-phase microextraction and gas chromatography-mass spectrometry. Eur Food Res Technol. 2016;224:67-74.

Cheng S, Li H, Jiang D, Chen C, Zhang T, Li Y, Wang H, Zhou Q, Li H, Tan M. Sensitive detection of trimethylamine based on dopant-assisted positive photoionization ion mobility spectrometry. Talanta. 2017;162:398-402.

daCosta KA, Vrbanac JJ, Zeisel SH. The measurement of dimethylamine, trimethylamine, and trimethylamine $\mathrm{N}$-oxide using capillary gas chromatography-mass spectrometry. Anal Biochem. 1990;187:234-9.

Erupe ME, Liberman-Martin A, Silva PJ, Malloy QGJ, Yonis N, Cocker DR III, PurvisRoberts $\mathrm{KL}$. Determination of methylamines and trimethylamine-N-oxide in particulate matter by non-suppressed ion chromatography. J Chromatogr A. 2010;1217:2070-3.

Gangam R, Pavlov J, Attygalle AB. Regulated in situ generation of molecular ions or protonated molecules under atmospheric-pressure helium-plasmaionization mass spectrometric conditions. J Am Soc Mass Spectrom. 2015;26: 1252-5.

Hassan I, Pavlov J, Errabelli R, Attygalle AB. Oxidative ionization under certain negative-ion mass spectrometric conditions. J Am Soc Mass Spectrom. 2017; 28:270-7.

Hindle F, Kuuliala L, Mouelhi M, Cuisset A, Bray C, Vanwolleghem M, Devlieghere F, Moureta G, Bocquet R. Monitoring of food spoilage by high resolution $\mathrm{THz}$ analysis. Analyst. 2018;143:5536-44.

Hyötyläinen T, Savola N, Lehtonen P, Riekkola ML. Determination of biogenic amines in wine by multidimensional liquid chromatography with online derivatisation. Analyst. 2001;126:2124-7.

Landfald B, Valeur J, Berstad A, Raa J. Microbial trimethylamine-N-oxide as a disease marker: something fishy? Microb Ecol Health Dis. 2017. https://doi. org/10.1080/16512235.

Li F, Liu HY, Xue CH, Xin XQ, Xu J, Chang YG, Xue Y, Yin LA. Simultaneous determination of dimethylamine, trimethylamine and trimethylamine- $\mathrm{N}$ oxide in aquatic products extracts by ion chromatography with nonsuppressed conductivity detection. J Chromatogr A. 2009;1216:5924-6.

Li M, Lee SH. Determination of trimethylamine in fish by capillary electrophoresis with electrogenerated tris(2,2'-bipyridyl)ruthenium(II) chemiluminescence detection. Luminescence. 2007;22:588-93.

Malle P, Eb P, Tailliez R. Determination of the quality of fish by measuring trimethylamine oxide reduction. Int J Food Microbiol. 1996;3:225-35.

Malle P, Tao SH. Rapid quantitative determination of trimethylamine using steam distillation. J Food Prot. 1987;50:756-60.

Namieśnik J, Jastrzębska A, Zygmunt B. Determination of volatile aliphatic amines in air by solid-phase microextraction coupled with gas chromatography with flame ionization detection. J Chromatogr A. 2003;1016:1-9.

Oetjen K, Karl H. Improvement of gas chromatographie determination methods of volatile amines in fish and fishery products. Deutsche LebensmittelRundschau. 1999;95:403-7.

Pavlov J, Attygalle AB. Direct detection of inorganic nitrate salts by ambient pressure helium-plasma ionization mass spectrometry. Anal Chem. 2013;85: 278-82.

Pedrosa-Menabrito A, Regenstein JM. Shelf-life extentension of fresh fish-a review part III-fish quality and methods of assessment. J Food Qual. 1990;13:209-23.

Podadera P, Ar as JAG, Lanfer-Marquez UM. Diagnosis of suspected trimethylaminuria by NMR spectroscopy. Clin Chim Acta. 2005;351:149-54.

Romero-González R, Alarcón-Flores MI, Vidal JLM, Frenich AG. Simultaneous determination of four biogenic and three volatile amines in anchovy by ultra-high-performance liquid chromatography coupled to tandem mass spectrometry. J Agric Food Chem. 2012;60:5324-9.

Seibel BA, Walsh PJ. Trimethylamine oxide accumulation in marine animals: relationship to acylglycerol storage. J Exp Biol. 2002;205:297-306.

Shim JE, Baek HH. Determination of trimethylamine in spinach, cabbage, and lettuce at alkaline $\mathrm{pH}$ by headspace solid-phase microextraction. J Food Sci. 2012; 7:C1071-6.

Timm M, Jørgensen BM. Simultaneous determination of ammonia, dimethylamine, trimethylamine and trimethylamine- $\mathrm{N}$-oxide in fish extracts by capillary electrophoresis with indirect UV-detection. Food Chem. 2002;76: 509-18.

Weerasinghe S, Pavlov J, Zhang Y, Attygalle AB. Direct detection of solid inorganic mercury salts at ambient pressure by electron-capture and reaction-assisted HePI mass spectrometry. J Am Soc Mass Spectrom. 2014;25: 149-53.
Xia H, Zhang Y, Pavlov J, Jariwala FB, Attygalle AB. Competitive homolytic and heterolytic decomposition pathways of gas-phase negative ions generated from aminobenzoate esters. J Mass Spectrom. 2016;51:245-53.

Yang Z, Attygalle AB. Aliphatic hydrocarbon spectra by helium ionization mass spectrometry (HIMS) on a modified atmospheric-pressure source designed for electrospray ionization. J Am Soc Mass Spectrom. 2011;22:1395-402.

Yang Z, Pavlov J, Attygalle AB. Quantification and remote detection of nitro explosives by helium plasma ionization mass spectrometry (HePI-MS) on a modified atmospheric-pressure source designed for electrospray ionization. J Mass Spectrom. 2012;47:845-52.

\section{Publisher's Note}

Springer Nature remains neutral with regard to jurisdictional claims in published maps and institutional affiliations.

\section{Submit your manuscript to a SpringerOpen ${ }^{\odot}$ journal and benefit from:}

- Convenient online submission

- Rigorous peer review

- Open access: articles freely available online

High visibility within the field

- Retaining the copyright to your article

Submit your next manuscript at $\boldsymbol{\nabla}$ springeropen.com 